\title{
Following Neuropathic Pain Route: Glial Alteration in the Thalamus
}

\author{
Altération de la fonction des cellules gliales thalamiques dans les douleurs neuropathiques
}

\author{
S. Abou Rachid $\cdot$ E. Nigi $\cdot$ A. Shiba $\cdot$ V. Zhukova \\ (C) Lavoisier SAS 2020
}

Résumé Les cellules gliales jouent un rôle important dans l'initiation et la maintenance de la sensation de la douleur. La plupart des études portant sur ce sujet ont été réalisées au niveau de la moelle épinière et relativement peu au niveau supraspinal et notamment thalamique. Les noyaux thalamiques traitent les messages nociceptifs avant d'être adressés au cortex ; en particulier, le noyau thalamique ventropostérolatéral (VPL) est impliqué dans les aspects sensoriels et discriminatifs du traitement de la douleur. L'article présenté par L. Blaszczyk et al. révèle les nouveaux rôles de la microglie et des astrocytes situés dans le VPL et impliqués dans la douleur neuropathique. Dans cette étude, Blasczyk et al. ont utilisé une ligation du nerf spinal L5/L6 chez le rat comme modèle du douleur neuropathique. Des allodynies statiques mécaniques et une hyperalgésie ont été observées chez les animaux après la chirurgie. Plusieurs analyses ont ensuite été effectuées sur les cellules du VPL. Une analyse morphométrique fondée sur les marqueurs gliaux, combinée à un comptage conventionnel et stéréologique de cellules, a indiqué une diminution transitoire de la population de microglies après 14 jours et suggère également une hypertrophie des astrocytes au $28^{\mathrm{e}}$ jour. La réactivité des microglies a été évaluée en utilisant leurs marqueurs spécifiques au $14^{\mathrm{e}}$ jour. Ces résultats révèlent un modèle d'activation séquentiel, sans précédent, des microglies et des astrocytes, pouvant aider à découvrir leur rôle dans l'apparition mais également le maintien de ce dysfonctionnement somatosensoriel.

Mots clés Douleur neuropathique - Thalamus · Astrocytes · Microglies · GFAP · iba-1

Neuropathic pain is a widespread condition that has a negative impact on life quality of patients and can promote mood

\footnotetext{
S. Abou Rachid · E. Nigi $(\bowtie) \cdot$ A. Shiba $\cdot$ V. Zhukova École universitaire de recherche interdisciplinaire sur la douleur (EURIDOL Graduate School of Pain),

Joint Master in Neuroscience, université de Strasbourg, faculté des sciences de la vie, 28 , rue Goethe,

F-67000 Strasbourg, France

e-mail : elena.nigi@etu.unistra.fr
}

disorders. Globally, around $7-10 \%$ of adults have pain with neuropathic characteristics. Among them, a quarter suffers from diabetes and $35 \%$ are affected by human immunodeficiency virus [1]. Despite the high importance of this problem, treatment for neuropathic pain is still challenging and pain processing in some brain regions remains unclear. In the pain pathway, thalamus integrates nociceptive information from lower structures and conveys it to the cortex. Emotional aspects of pain are processed in the medial thalamic nucleus (MT), whereas ventral posterolateral thalamic nucleus (VPL) is involved in pain sensitization [2]. Nowadays, the role of thalamic non-neuronal cells has been reported as important in underlying mechanisms $[3,4]$. Generally, astrocytes and microglia are involved in onset and maintenance of nociception producing hypertrophy, hypersensitivity, and inflammation. In particular, astrocytes can release pro-inflammatory factors like cytokines, prostaglandins, neurotrophins, neuromodulators such as ATP and NO and specific transcriptional factors (STAT3, NFאB) to modulate the activity of surrounding cells upon glia-glial and neuron-glial interactions [5]. On the other hand, microglia is a resident of immune system in CNS, which enhance painsensitivity via a number of synergistic neuro-glial interactions $[3,4]$. In the peripheral neuropathic pain model, the spinal cord microglia have been implicated in the initiation phase of peripheral nerve injury-induced pain [6,7] while spinal astrocytes in the maintenance of its symptoms [8]. However, the role played by microglia and astrocytes at the thalamic level remains unclear.

To study the implication of these thalamic non-neuronal cells in neuropathic pain, Blaszczyk et al. utilized L5-L6 spinal nerve ligation rodent model of neuropathy [9]. The surgery allowed generation of neuropathic pain in rats by tightly ligating the two spinal nerves. Two other groups of animals were used for comparison: naïve, rats without any treatment, and sham, the group that underwent the whole surgery procedure without spinal nerve ligation (SNL). The neuropathic effects were measured 2 weeks (D14) and 4 weeks (D28) after the procedure with the von Frey hair stimulation. This behavioral nociception assay tested the pain sensitivity of animals after stimulation of the hind paws with a nylon rod 
varying in diameter. The stimulation demonstrated progressive mechanical allodynia and hyperalgesia as well as ambulatory pain (evaluated by using the dynamic weight bearing apparatus) in the ipsilateral hind paws of the SNL animals.

Since the study focused on VPL microglia and astrocytes activation, specifically in the subregion that receives projections from the hindlimb, different markers were selected to assess gliosis, or morphological changes in these cells: GFAP and S100B for astrocytes, iba-1 for microglia. In addition, the expression of specific microglial genes connected to cell reactivity (CX3CL1, CTSS, and CX3CR1) was also investigated by measuring mRNA and protein levels.

In case of microglia, the authors observed intriguing results: previous studies in the spinal cord [6,7] demonstrated that microglial activation after peripheral nerve injury is characterized by hypertrophy and cell number increase. In addition to these changes, molecular evidences of cell reactivity were also detected. In this experiment, authors focused on the VPL subregion and conducted quantitative real-time PCR to visualize the mRNA levels and Western blot to clarify the protein levels. As a result, increased expressions of the wellknown reactivity markers CXC3CR1, CXC3CL1, and CTSS were detected. These data are in agreement with other studies in which microglia activation in the thalamus was observed $14,16,28$, and 34 days after the peripheral nerve injury in animals [9] and even for 2 years in humans with lumbar chronic pain [10]. On the other hand, the morphometric analysis of iba-1 immunostaining, combined with the two types of cell count, suggested a transient decrease in the microglia population (D14) followed by a re-establishment (D28). The number of microglial cells was negatively correlated with ambulatory pain suggesting a possible link between number of cells and pain symptoms.

Therefore, compared to the microglial activation observed in the spinal cord, the typical molecular activation of the cells is still conserved in this area of the VPL, but accompanied by this unpredicted transient decrease in cell number. The result is remarkable because it points out a

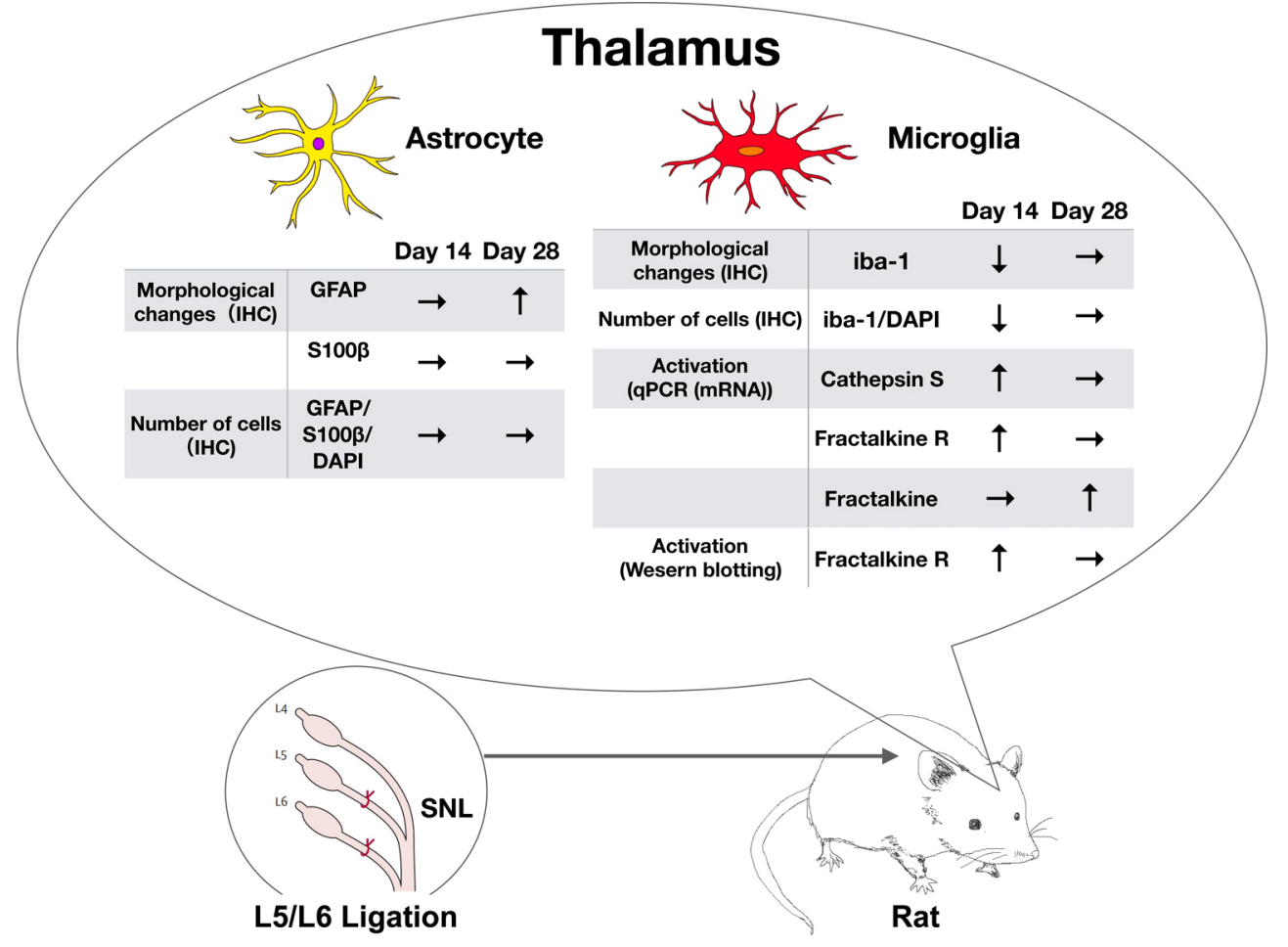

Fig. 1 Summary tables of the sequential alteration in astrocytes and microglia in the VPL after SNL.

D14: 14 days after surgery. D28: 28 days after surgery. Table on the left: results of immunohistochemistry (IHC) in astrocytes. This morphometric analysis displayed a significant increase of GFAP in the VPL of SNL animals at D28. O significant change in the number of GFAP/S100B/DAPI positive cells per surface area was observed. Table on the right: results of IHC, qPCR, and Western Blotting in microglia. The morphometric analysis revealed a significant decrease of iba-1 immunofluorescent surfaces in the VPL at D14. The number of iba-1/DAPI immunopositive cells per surface area was also decreased ad D14.

As qPCR results, significant increase in mRNA expression of Cathepsin S receptor (CTSS) and Fractalkine receptor (CXCR1) at D14 were observed. The mRNA expression of Fractalkine (CX3CL1) was significantly increased at D28. Western blotting exhibited that Fractalkine receptor (CX3CR1) protein level was significantly increased in SNL animals at D14 
potential new type of microgliosis in the thalamus in neuropathic condition. Different assumptions have been made regarding to this particular pattern. For instance, the decrease in the iba-1 labeled area could be due to (a) a transient down regulation of iba-1 expression, (b) an apoptosis step followed by microglial genesis, and (c) migration of the cells. The first two hypotheses seem unlikely since iba-1 mRNA analysis revealed unchanged expression and no sign of apoptosis was detected in the VPL, while the last possibility is yet to be explored.

In the case of astrocytic alterations, the morphometric analysis of GFAP immunostaining combined with the cell counting procedure, revealed an increase in GFAP labeled area and same number of cells at D28. This suggests a progressive hypertrophy in the astrocytes and probably their delayed activation in thalamus in this case of pathology. Blaszczyk et al. assumed that the sequential activation pattern described for spinal glia could also be applied to the thalamic microglia and astrocytes in the SNL model.

Finally, recent transcriptomic studies showed that there are about seven subtypes of astrocytes in the mouse brain with characteristic markers and a range of active states in pathological conditions $[11,12]$. Moreover GFAP, which is widespread utilized for astrogliosis analysis, appears to be not so specific: not all astrocytes express this marker $[5,13]$, as well as it can also be found in satellite glial cells in the dorsal root ganglia and Schwann cells in the sciatic nerve [5]. Additionally, it is important to pay attention on the long-term duration of astrogliosis and sex influence on glial alteration at neuropathic pain described in spinal cord research works $[14,15]$.

In conclusion, this study shows that neuropathic pain leads to the sequential alteration of microglia and astrocytes in ventral posterolateral thalamic nucleus. This phenomenon could be related to pain processing as well as sensitization of the thalamus to mechanical stimuli. However, underlying mechanisms are currently unknown. Once these mechanisms will be identified, they will help to detect novel targets for neuropathic pain treatment (Fig. 1).

Acknowledgments This journal club report has been written in the course of the Joint Master in Neuroscience training program (teaching unit: fundamental in neuroscience) with the support of the French National Research Agency (ANR) through the Programme d'investissement d'avenir (contract ANR-17-EURE-0022, EURIDOL graduate school of pain)
Conflicts of interests: The authors declare that they have no conflict of interest

\section{References}

1. Murnion B (2018) Neuropathic pain: current definition and review of drug treatment. Aust Prescr 41:60-3

2. Garcia-Larrea L, Peyron R (2013) Pain matrices and neuropathic pain matrices: a review. Pain 154:S29-S43

3. Chen G, Zhang YQ, Qadri YJ, et al (2018) Microglia in pain: detrimental and protective roles in pathogenesis and resolution of pain. Neuron 100:1292-311

4. Ji RR, Berta T, Nedergaard M (2013) Glia and pain: is chronic pain a gliopathy? Pain $154:$ S10-28

5. Ji RR, Donnelly CR, Nedergaard M (2019) Astrocytes in chronic pain and itch. Nat Rev Neurosci 20:667-85

6. Jin SX, Zhuang ZY, Woolf CJ, et al (2003) p38 mitogen-activated protein kinase is activated after a spinal nerve ligation in spinal cord microglia and dorsal root ganglion neurons and contributes to the generation of neuropathic pain. J Neurosci 23:4017-22

7. Ledeboer A, Sloane EM, Milligan ED, et al (2005) Minocycline attenuates mechanical allodynia and proinflammatory cytokine expression in rat models of pain facilitation. Pain 115:71-83

8. Zhuang ZY, Wen YR, Zhang DR, et al (2006) A peptide c-Jun Nterminal kinase (JNK) inhibitor blocks mechanical allodynia after spinal nerve ligation: respective roles of JNK activation in primary sensory neurons and spinal astrocytes for neuropathic pain development and maintenance. J Neurosci 26:3551-60

9. Blaszczyk L, Maitre M, Lesté-Lasserre T, et al (2018) Sequential alteration of microglia and astrocytes in the rat thalamus following spinal nerve ligation. J Neuroinflammation 15:349

10. Loggia ML, Chonde DB, Akeju O, et al (2015) Evidence for brain glial activation in chronic pain patients. Brain 138:604-15

11. Zeisel A, Hochgerner H, Lonnerberg P, et al (2018) Molecular architecture of the mouse nervous system. Cell 174:999-1014.e1022

12. Hammond TR, Dufort C, Dissing-Olesen L, et al (2019) Singlecell RNA sequencing of microglia throughout the mouse lifespan and in the injured brain reveals complex cell-state changes. Immunity 50:253-271.e256

13. Bushong EA, Martone ME, Jones YZ, et al (2002) Protoplasmic astrocytes in CA1 stratum radiatum occupy separate anatomical domains. J. Neurosci 22:183-192

14. Zhang J, De Koninck Y (2006) Spatial and temporal relationship between monocyte chemoattractant protein-1 expression and spinal glial activation following peripheral nerve injury. J Neurochem 97:772-83

15. Taves S, Berta T, Liu DL, et al (2016) Spinal inhibition of p38 MAP kinase reduces inflammatory and neuropathic pain in male but not female mice: sex-dependent microglial signaling in the spinal cord. Brain Behav Immun 55:70-81 